Check for updates

Cite this: React. Chem. Eng., 2019, 4,884

Received 22nd December 2018, Accepted 22nd March 2019

DOI: $10.1039 / \mathrm{c} 8 \mathrm{re} 00351 \mathrm{c}$

rsc.li/reaction-engineering

\title{
Rapid synthesis of gold nanoparticles with carbon
monoxide in a microfluidic segmented flow \\ Rapid synthesis of gold nanoparticles with carbon
monoxide in a microfluidic segmented flow system $\dagger$
}

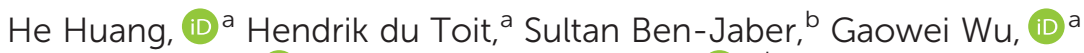 \\ Luca Panariello, id a Nguyen Thi Kim Thanh, iD cd \\ Ivan P. Parkin iD ${ }^{b}$ and Asterios Gavriilidis iD *a
}

\begin{abstract}
A microfluidic reactor was developed to enhance the speed (reaction time $<4 \mathrm{~min}$ ) and control of the synthesis of gold nanoparticles (3-25 nm) with or without capping agents using carbon monoxide as gaseous reductant, which is easy to remove from the reaction mixture by venting. Gas-liquid segmented flow was formed inside a $1 \mathrm{~mm}$ inner diameter coiled flow inverter with aqueous gold precursor and the reducing gas to produce gold nanoparticles with polydispersity as low as $5 \%$. The uncapped gold nanoparticles make the product attractive for surface-enhanced Raman scattering, and showed an average enhancement factor of $1.94 \times 10^{5}$. Various capping agents (tri-sodium citrate, polysorbate 80, oleylamine and poly(ethyleneglycol) 2-mercaptoethyl ether acetic acid) and different operational parameters were also tested, demonstrating that the proposed synthesis is flexible and can continuously produce a variety of gold nanoparticles, with potential for other applications.
\end{abstract}

\section{Introduction}

Due to their unique optical, electronic, catalytic and biocompatibility properties, gold nanoparticles have a wide range of applications in many areas such as catalysis, ${ }^{1}$ analytical chemistry, $^{2}$ medical diagnostics and therapies. ${ }^{3}$ Gold ions $\left(\mathrm{Au}^{3+}\right.$ or $\left.\mathrm{Au}^{+}\right)$in solution are typically reduced by either a strong reducing agent $\left(\right.$ e.g., $\left.\mathrm{NaBH}_{4}\right)$ to form gold nanoparticles under $5 \mathrm{~nm}$ in diameter, ${ }^{4}$ or mild reducing agent (e.g., tri-sodium citrate) $)^{5}$ to form larger gold nanoparticles with sizes ranging between 10-40 $\mathrm{nm}$. Once formed, they generally require stabilisation to prevent aggregation. This is achieved using capping agents which bind temporally or permanently to the gold nanoparticle surfaces and provide steric or electrostatic repulsion. ${ }^{6}$ In general, the formation of gold nanoparticles is divided into two stages: nucleation and

\footnotetext{
${ }^{a}$ Department of Chemical Engineering, University College London, Torrington Place, London, WC1E 7JE, UK. E-mail: a.gavriilidis@ucl.ac.uk

${ }^{b}$ Department of Chemistry, University College London, 20 Gordon Street, London, WC1H OAJ, UK

${ }^{c}$ Biophysics Group, Department of Physics and Astronomy, University College London, Gower Street, London, WC1E 6BT, UK

${ }^{d}$ UCL Healthcare Biomagnetic and Nanomaterials Laboratories, 21 Albemarle Street, London, W1S 4BS, UK

$\dagger$ Electronic supplementary information (ESI) available. See DOI: 10.1039/ c8re00351c
}

growth. ${ }^{7}$ A key element to obtain monodisperse particles is the separation between nucleation and growth processes by the transition between gold species with different reactivity to terminate nucleation and encourage growth on the existing gold surface. ${ }^{8}$ A detailed study into gold nanoparticle synthesis by reduction with gaseous carbon monoxide (CO) in a batch system has been presented by Young et al. ${ }^{9}$ The CO was introduced via a gas diffuser with $60 \mu \mathrm{m}$ pore size into the aqueous $\mathrm{HAuCl}_{4}$ solution at different flow rates. Compared with typical gold nanoparticle synthesis routes, which rely on liquid reducing agents, reduction by CO has various advantages, such as no impurity or side product from reducing agent is left after the synthesis, room temperature synthesis and shorter reaction times (3-5 $\mathrm{min})$ compared to the typical Turkevich method (around $30 \mathrm{~min}){ }^{5}$ However, mixing between $\mathrm{CO}$ and aqueous $\mathrm{HAuCl}_{4}$ solution in a batch system, where small bubbles of gaseous reducing agent are formed and dispersed in the solution, could lead to coalescence of the CO bubbles. The changing bubble size resulting from coalescence leads to decreasing surface-to-volume ratio, which can influence the reduction rate at different locations in the batch reactor leading to nanoparticle polydispersity. The use of microfluidic reactors can alleviate this problem. TaifurRahman et al. utilized CO in a membrane-based droplet microfluidic system to produce $10 \mathrm{~nm}$ gold nanoparticles, as well as grow $\mathrm{Au}$ shells on silica nanoparticles with preattached gold nanoparticle seeds. ${ }^{10}$ The residence time was 
controlled by the gas-liquid contact time and was much larger than the calculated mixing time, enabling controlled dosing of CO into each droplet.

In this study, we present a simple method of producing gold nanoparticles in a coiled flow inverter (CFI) reactor at room temperature via $\mathrm{CO}$ reduction. Such a multiphase microfluidic reactor with a large surface-to-volume ratio is expected to enhance the mass transfer between gas and liquid. ${ }^{11}$ Additionally, the combination of segmented flow and CFI should improve mixing and narrow the residence time distribution, ${ }^{12}$ resulting in more monodisperse gold nanoparticles.

\section{Experimental}

All the chemicals were purchased from Sigma-Aldrich and used without any further treatment or purification. A schematic of the segmented flow system utilised in this work is shown in Fig. S1.† A CFI made of fluorinated ethylene propylene (FEP) tubing, $1 \mathrm{~mm}$ internal diameter (I.D.), $2 \mathrm{~mm}$ outside diameter (O.D.), $3.6 \mathrm{~m}$ length (VICI Jour) was utilized. There were 100 coils in total formed on a PTFE support plate $(9.5 \mathrm{~cm} \times 7.5 \mathrm{~cm})$ and the coil diameter was $1 \mathrm{~cm}$. A $90^{\circ}$ bend between successive coiled sections, each one containing 5 coils, produced a compact design, with the added advantage of improving mixing and residence time distribution. ${ }^{13}$ An aqueous $\mathrm{HAuCl}_{4}$ solution was mixed with $\mathrm{CO}$ gas $(99.5 \%$, BOC gases) through a Tefzel T-junction (0.5 mm I.D., P632, IDEX), which then formed segmented flow inside the CFI at atmospheric pressure. The liquid flow rate was fixed at 0.5 $\mathrm{ml} \mathrm{min}^{-1}$ using a syringe pump (Legato 270P, KD Scientific; $25 \mathrm{ml}$ glass syringe, Mod 1025 Syr 25Ml Tll Terminus, Biochrom Ltd.) and different liquid to gas volumetric flow rate ratios ( 2 to 20) were attained by tuning the gas flow rate in

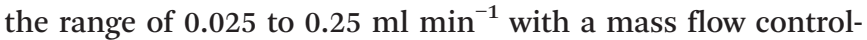
ler (EL Flow, Bronkhorst). The residence time was adjusted to 3-5 min by altering only the gas flow rate. The flow inside the reactor was regarded as plug flow, since the liquid slugs where mixing occurred by recirculation, were isolated from each other due to the wall hydrophobicity. The residence time was measured based on the time for one slug to pass through the whole CFI. The solution $\mathrm{pH}$ was measured by a $\mathrm{pH}$ meter (SevenCompact ${ }^{\mathrm{TM}} \mathrm{pH} / \mathrm{Ion}$ S220).

UV-Vis absorption spectra of gold nanoparticles were recorded immediately after collection from the reactor using an Ocean Optics UV-Vis spectrometer (USB 2000+ spectrometer and DT-Mini-2-GS light source). The resulting gold nanoparticle size was measured by differential centrifugal sedimentation (DCS) (CPS 24000 Disc Centrifuge, CPS Instruments); the total number of particles counted was in the order of $10^{11}$. Transmission electron microscopy (TEM) (Jeol 2010) at $200 \mathrm{kV}$ was used to determine morphology, particle size and polydispersity (defined as standard deviation over the average particle size). Zeta potential measurement was performed with a data acquisition time of $10 \mathrm{~s}$ with a dynamic light scattering apparatus (DLS) (DelsaMax-Pro, Beckman Coulter) using the supplied flow cell system in batch mode at $22{ }^{\circ} \mathrm{C}$. For the synthesis at different initial $\mathrm{pH}$, the precursor was mixed with $\mathrm{K}_{2} \mathrm{CO}_{3}$ one day in advance to ensure the gold species achieved equilibrium. ATR-FTIR spectroscopy of liquid sample was performed using a PerkinElmer 1605 FT-IR spectrometer with a resolution of $0.5 \mathrm{~cm}^{-1}$ and wavenumber range $0-5000 \mathrm{~cm}^{-1}$. Raman spectra were obtained with a Renishaw Raman inVia microscope with a $633 \mathrm{~nm}$ He-Ne excitation laser $(1.9 \mathrm{eV}, 0.7 \mathrm{~mW}$, pore size $\sim 4.4 \mu \mathrm{m}^{2}$ ). A Rhodamine 6G (Rh6G) solution with concentration $4 \times 10^{-6} \mathrm{M}$ was mixed with gold nanoparticle solutions at a volume ratio of $2 / 3$ and then stirred for $20 \mathrm{~min}$ to allow enough time for the Rh6G molecules to bind onto the gold nanoparticle surface. The mixed solutions were dropped onto glass substrates and dried at ambient conditions to create surface-enhanced Raman scattering (SERS) hotspots. The commercial citrate-capped gold nanoparticles used for comparison were from BBI Solutions (UK).

\section{Results and discussion}

\section{Synthesis of gold nanoparticles without capping agents}

Effect of liquid to gas flow rate ratio and $\mathrm{HAuCl}_{4}$ concentration. The overall reaction between gold precursor and CO as proposed by Pretzer et al. ${ }^{14}$ is

$$
\begin{aligned}
2\left[\mathrm{AuCl}_{4-x}(\mathrm{OH})_{x}\right]^{-} & +3 \mathrm{CO}+3 \mathrm{H}_{2} \mathrm{O} \rightarrow 2 \mathrm{Au}^{0}+3 \mathrm{CO}_{2}+6 \mathrm{H}^{+} \\
& +2 x \mathrm{OH}^{-}+2(4-x) \mathrm{Cl}^{-}
\end{aligned}
$$

The conditions of $0.54 \mathrm{mM}$ initial concentration of gold precursor and the highest liquid to gas volumetric flow rate ratio $(\mathrm{L} / \mathrm{G})$ of 20 , gave the lowest $\mathrm{CO} / \mathrm{Au}^{3+}$ inlet molar flow rate ratio of 3.8. Considering a stoichiometry of $\mathrm{CO} / \mathrm{Au}^{3+}$ for the reduction reaction of $3 / 2$, it is evident that the $\mathrm{CO}$ available is in significant excess for all experiments. Thus, the gaseous $\mathrm{CO}$ acted as a reservoir to continuously dose the liquid slugs throughout the whole reduction process. Fig. 1 shows the product characterization results from a $0.27 \mathrm{mM}$ $\mathrm{HAuCl}_{4}$ solution at different liquid to gas flow rate ratios, at room temperature (maintained between 20-22 ${ }^{\circ} \mathrm{C}$ ). Nonspherical particles were observed which is consistent with previous literature, ${ }^{9,15}$ rather than spherical shape from citrate reduction. The lowest polydispersity (based on Differential Centrifugal Sedimentation (DCS) analysis) observed was $<5 \%$, which is smaller than the CO-produced gold nanoparticles in batch by Young et al. ${ }^{9}$ with similar initial concentration of gold precursor ( $0.3 \mathrm{mM}$, polydispersity of $11 \%)$, likely due to the good mixing provided by the recirculation in the liquid slugs ${ }^{11}$ and helical flow inversion. ${ }^{12}$ Experiments with a slightly larger (internal diameter $1.5 \mathrm{~mm}$ ) glass tube with 4 coils and no flow inversion (see section 2, ESI $\dagger$ ), using the same experimental conditions (residence time, reactant concentration and liquid to gas volumetric flow rate ratio) led to similar nanoparticle size $(7.8 \mathrm{~nm}$ in coiled glass tube vs. $7.7 \mathrm{~nm}$ in FEP CFI). However, the polydispersity increased from $4.1 \%$ in the CFI to $14.2 \%$ in the glass tube, likely due to 

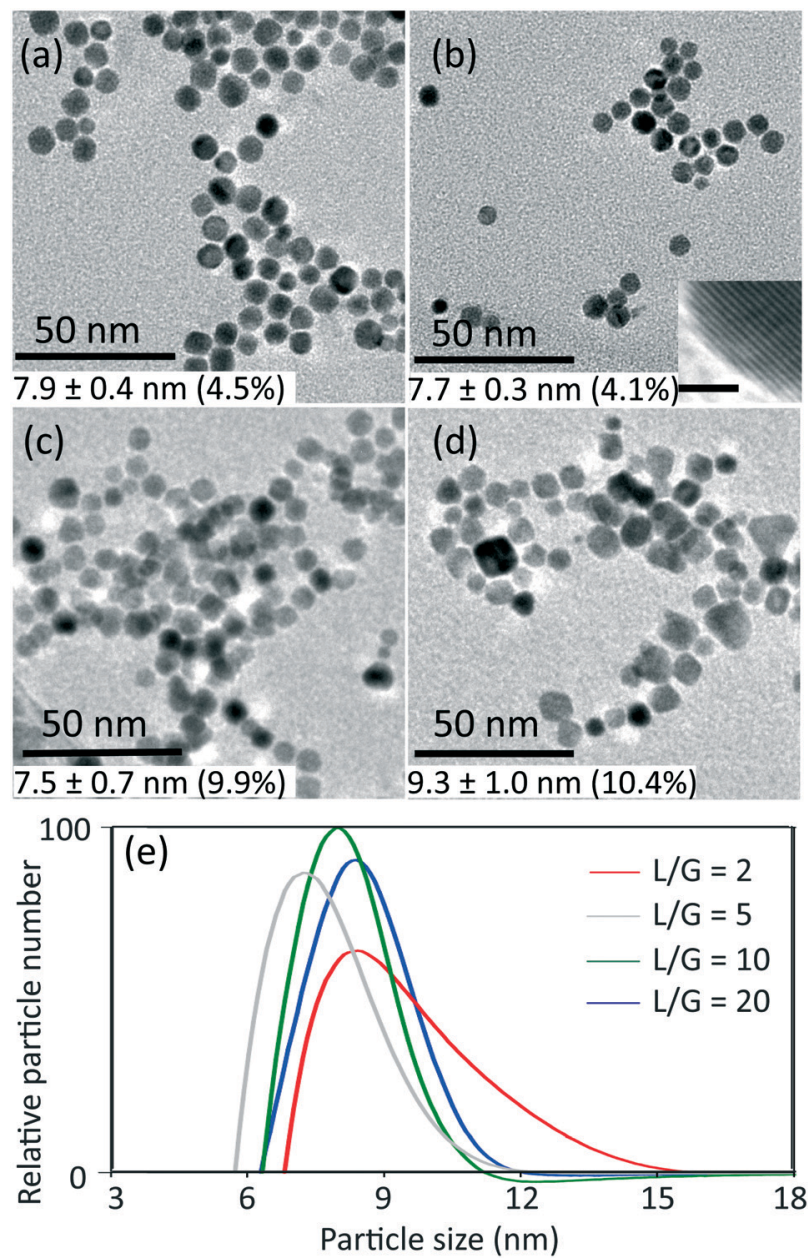

Fig. 1 TEM images of gold nanoparticles synthesized at different liquid to gas volumetric flow rate ratios (L/G): a) 20 (residence time 5 $\mathrm{min}$ ), b) 10 (residence time $4.4 \mathrm{~min}$ ), c) 5 (residence time $4.2 \mathrm{~min}$ ) and d) 2 (residence time $3.4 \mathrm{~min}$ ) with inlet concentration of $\mathrm{HAuCl}_{4} 0.27$ $\mathrm{mM}$, at room temperature. Insert in b) shows the lattice plane spacing of a gold nanoparticle, which indicates Au [111] surface (scale bar 1 $\mathrm{nm}$ ). e) Particle size distribution obtained from DCS (normalised by area in each curve) for samples obtained at the L/G indicated. The values of average particle size and polydispersity in the TEM images (ad) are obtained from DCS (e).

the inferior mixing in the slugs and the existence of liquid film.

For $\mathrm{L} / \mathrm{G}$ ratio in the range of 20 to 2 , the flow patterns remained as segmented flow, but with different liquid slug lengths (see Fig. S3, ESI $\dagger$ ). Increasing the gas flow rate with constant liquid flow rate led to more frequent and shorter liquid slugs with larger interfacial area-to-volume ratio, which enhanced the mass transfer between gas and liquid phase. The volumetric mass transfer coefficient increased (see section 3, ESI $\dagger$ ) as the $\mathrm{L} / \mathrm{G}$ decreased from 20 to 2 , leading to faster dosing of $\mathrm{CO}$ into the liquid phase.

The effect of initial concentration of $\mathrm{HAuCl}_{4}$ on particle size and size distribution was studied and the results are shown in Fig. 2. Since DCS uses higher sample volume (total counted particle number is much larger than those observed

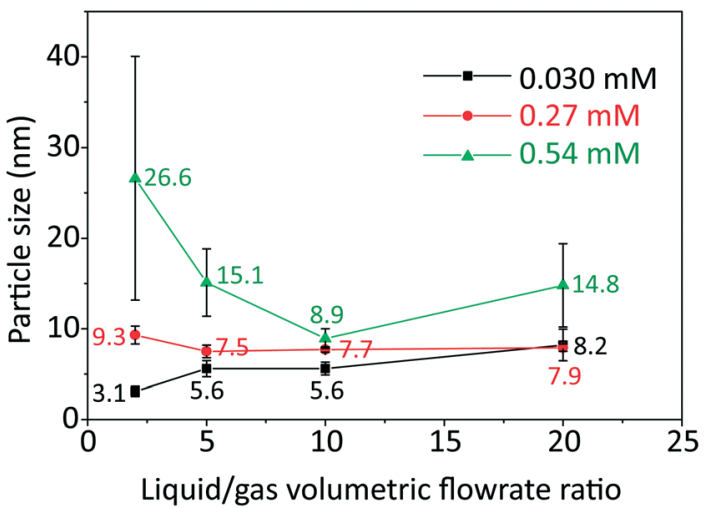

Fig. 2 Particle size (labelled near the points) and standard deviation of size distribution (denoted by error bar) obtained from TEM and DCS (Fig. S4 and S5, ESI $\dagger$ ) as a function of liquid to gas volumetric flow rate ratio, with inlet concentrations of $\mathrm{HAuCl}_{4}$ indicated, at room temperature and residence time $3-5 \mathrm{~min}$.

in TEM), most of the particle size and size distribution measurements were based on DCS for higher accuracy. However, since DCS is limited to gold nanoparticles above $3 \mathrm{~nm},{ }^{16}$ the particle size at $0.030 \mathrm{mM}$ concentration of gold precursor was based on TEM (see Fig. S4, ESI $\dagger$ ).

As the $\mathrm{L} / \mathrm{G}$ ratio decreases, the mass transfer becomes faster, as discussed above. Thus, a higher overall CO concentration in the slugs is expected for low $\mathrm{L} / \mathrm{G}$ ratios. As the increase in concentration of $\mathrm{CO}$ acidifies the solution, ${ }^{14}$ the $\mathrm{pH}$ decreases for lower values of the $\mathrm{L} / \mathrm{G}$ ratio. In light of the above, we can interpret the trends of particle size in Fig. 2, based on the effect of $\mathrm{pH}$ on the gold species present in solution.

For $\mathrm{HAuCl}_{4}$ concentrations of $0.54 \mathrm{mM}$ and $0.27 \mathrm{mM}$, the observed trend of the nanoparticle size and polydispersity $v s$. the $\mathrm{L} / \mathrm{G}$ ratio (low $\mathrm{L} / \mathrm{G}$ ratios lead to low $\mathrm{pH}$ ) is analogous to that reported by Kettemann et al. ${ }^{17}$ who observed a minimum in particle size and polydispersity when varying the $\mathrm{pH}$ of the Turkevich synthesis. At low $\mathrm{pH}$ the reactivity of $\mathrm{HAuCl}_{4}$ is high, ${ }^{8}$ hence the separation of nucleation and growth steps is unlikely. This results in polydisperse and large particles. As the $\mathrm{L} / \mathrm{G}$ ratio increases, the $\mathrm{pH}$ increases and this enables a decoupling of nucleation and growth steps, leading to smaller size and more monodisperse nanoparticles. If one increases the $\mathrm{pH}$ beyond a certain point, the redistribution of the precursor between $\mathrm{AuCl}_{4}{ }^{-}$and $\mathrm{AuCl}_{4-x} \mathrm{OH}_{x}{ }^{-}$changes in favor of the more hydroxylated forms. ${ }^{8}$ The latter are less reactive and lead to larger nanoparticles (since nucleation has slowed down) and higher polydispersity (due to overlapping of nucleation and growth). So, the minimum in particle size and polydispersity observed in Fig. 2 for $0.54 \mathrm{mM}$ and 0.27 $\mathrm{mM}$ precursor concentration is attributed to optimal $\mathrm{pH}$ conditions. The experiment at $0.54 \mathrm{mM} \mathrm{HAuCl}$ and $\mathrm{L} / \mathrm{G}=10$ showing a minimum particle size $(8.9 \pm 1.1 \mathrm{~nm}, 12.4 \%)$ was repeated to confirm that a minimum truly existed. The repeated experiment produced a size and polydispersity of 8.6 $\pm 1.4 \mathrm{~nm}, 16.5 \%$. 
One should also note that the position of the minimum in the nanoparticle size vs. L/G data in Fig. 2, shifts to the left for decreasing precursor concentration. This agrees with the proposed interplay between the nucleation/growth mechanism and mass transfer: the initial $\mathrm{pH}$ of the solution is higher for lower initial concentration of $\mathrm{HAuCl}_{4}$, hence the $\mathrm{pH}$ that minimizes the particle dispersity by separating nucleation and growth is reached at a lower value of $\mathrm{L} / \mathrm{G}$ ratio. For a $\mathrm{HAuCl}_{4}$ concentration of $0.03 \mathrm{mM}$ the shift of the minimum to the left causes the corresponding $\mathrm{L} / \mathrm{G}$ ratio to coincide with (or be lower than) the lowest value of $\mathrm{L} / \mathrm{G}$ employed; at $\mathrm{L} / \mathrm{G}=2$ the smallest nanoparticle size was obtained $(3.1 \pm$ $0.5 \mathrm{~nm})$.

Effect of solution pH. If the formation of nuclei and particle growth occur in parallel, then higher polydispersity is expected. It is known that the reactivity of $\mathrm{HAuCl}_{4}$ species decreases with the equilibrium of species shifting to $\left[\mathrm{AuCl}_{x}(\mathrm{OH})_{4-x}\right]^{-}$with increasing $\mathrm{pH}^{18}$ It has also been shown that during CO reduction, the more hydroxyls the $\mathrm{Au}(\mathrm{III})$ complex contains, the less reactive it is. ${ }^{9}$ Thus, the reduction rate and thus nucleation is affected by the initial $\mathrm{pH}$ of the $\mathrm{HAuCl}_{4}$ solution. As the zeta potential of the gold nanoparticles obtained before $\mathrm{pH}$ tuning without stabilising surfactants was $+12 \mathrm{mV}$, the $\mathrm{pH}$ range studied was between 3-7 to avoid destroying the charge stability in the solution (the colour of the solution with higher $\mathrm{pH}$ changed from red to purple, indicating aggregation). ${ }^{2}$ Fig. 3 shows the characterization of gold nanoparticles synthesized at different initial $\mathrm{pH}$ of $\mathrm{HAuCl}_{4}$ tuned by the addition of $\mathrm{K}_{2} \mathrm{CO}_{3}$. The average particle size at $\mathrm{pH}=4(9.8 \mathrm{~nm})$ was slightly larger than the gold nanoparticles obtained at $\mathrm{pH}=3(9.3 \mathrm{~nm})$ (the difference was statistically significant with $P$ value $<0.001$ by unpaired $t$-test, due to the high total particle number in the order of $10^{11}$ ). We attribute this decreased particle size (from $9.8 \mathrm{~nm}$ to $9.3 \mathrm{~nm}$ ) to a faster nucleation rate at $\mathrm{pH}=3$, due to the higher amount of highly reactive gold species $\left[\mathrm{AuCl}_{4}\right]^{-}$compared to the dominant species of $\left[\mathrm{AuCl}_{3}(\mathrm{OH})\right]^{-}$at $\mathrm{pH}=4 .^{17}$ At initial $\mathrm{pH}>$ 4.0, the nucleation rate decreased and nucleation and growth occurred in parallel leading to increased polydispersity $(14.6 \%$ at $\mathrm{pH}=5.1$ and $20.7 \%$ at $\mathrm{pH}=6.7)$. Furthermore, altering the $\mathrm{pH}$ via the addition of $\mathrm{K}_{2} \mathrm{CO}_{3}$ increased the ionic strength of the solution, lowering the aggregation barrier. The increase in the $\mathrm{pH}$ also increased the solubility of $\mathrm{CO}$, hence speeding up the reduction. All these effects could lead to uncontrollable aggregation and hence to larger particle size and polydispersity.

Surface-enhanced Raman scattering (SERS) performance of gold nanoparticles. In order to demonstrate the applicability of the gold nanoparticles synthesized, they were tested for SERS. It is widely accepted that the Raman signal amplification with the aid of metal particles (typically $\mathrm{Ag}$ or $\mathrm{Au}$ ) is due to the localized surface plasmon resonance (LSPR) on the surface of metal particles. ${ }^{19}$ To achieve better enhancement, it is crucial to deposit gold nanoparticles on a substrate to create "hotspots" with narrow gaps between neighbouring
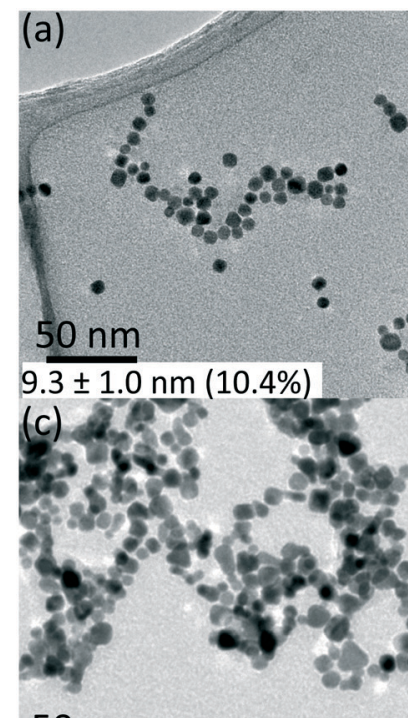

$50 \mathrm{~nm}$

$10.9 \pm 1.6 \mathrm{~nm}(14.6 \%)$

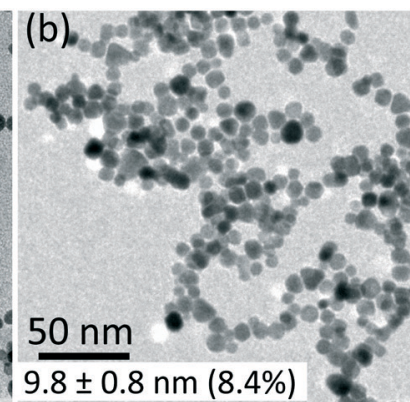

(d)

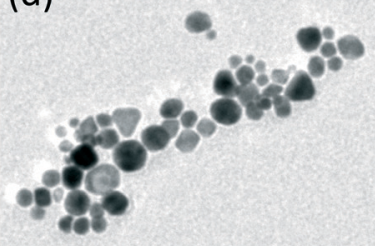

$50 \mathrm{~nm}$

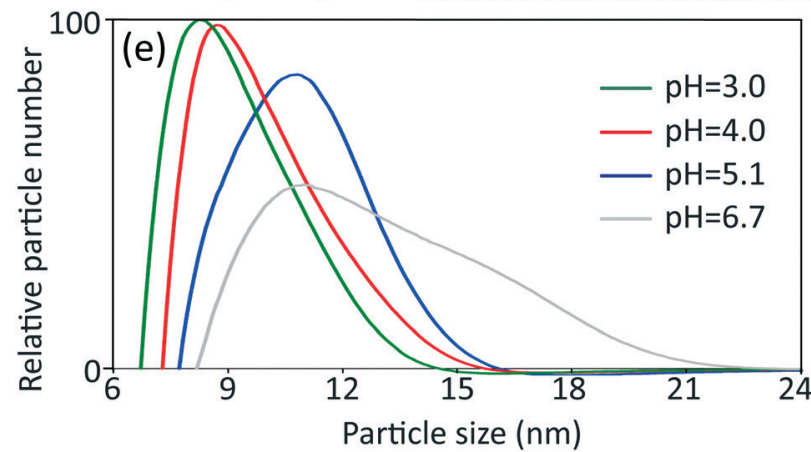

Fig. 3 TEM images of gold nanoparticles synthesized at different initial $\mathrm{pH}$ : a) 3.0 , b) 4.0 , c) 5.1 and d) 6.7 , with inlet concentration of $\mathrm{HAuCl}_{4} 0.27 \mathrm{mM}$, liquid to gas volumetric flow rate ratio 2 and room temperature. e) Particle size distribution from DCS (normalised by area in each curve) for samples obtained at initial $\mathrm{pH}$ indicated. The values of average particle size and polydispersity indicated in the TEM images (a-d) are obtained from DCS (e).

particles. ${ }^{20}$ In the TEM images in Fig. 1, it is seen that in the absence of any capping agent, the gold nanoparticles formed by $\mathrm{CO}$ reduction are in close proximity after drying; hence it is expected to be easy to create "hotspots". Additionally, the Raman signal decays exponentially with the distance between the metal surface and analyte molecules. ${ }^{21}$ The gold nanoparticles without capping agents provide free sites to adsorb the molecules, which also gives higher enhancement. The SERS performance of CO-produced and commercial citratecapped gold nanoparticles with different particle sizes is shown in Fig. 4. The average enhancement factor (AEF) was calculated from three intensities with different Raman shifts (611 $\mathrm{cm}^{-1}, 1359 \mathrm{~cm}^{-1}$ and $1509 \mathrm{~cm}^{-1}$ ) (see Table S3, ESI $\dagger$ ). The CO-produced gold nanoparticles with an average size of $26.6 \mathrm{~nm}$ (obtained from $0.54 \mathrm{mM}$ initial concentration of gold precursor at $\mathrm{L} / \mathrm{G}=2$ in Fig. 2) gave the highest enhancement with an AEF of $1.94 \times 10^{5}$, as it is in the optimal size range $(20-100 \mathrm{~nm})$ for SERS. ${ }^{22}$ Compared to commercial 30 


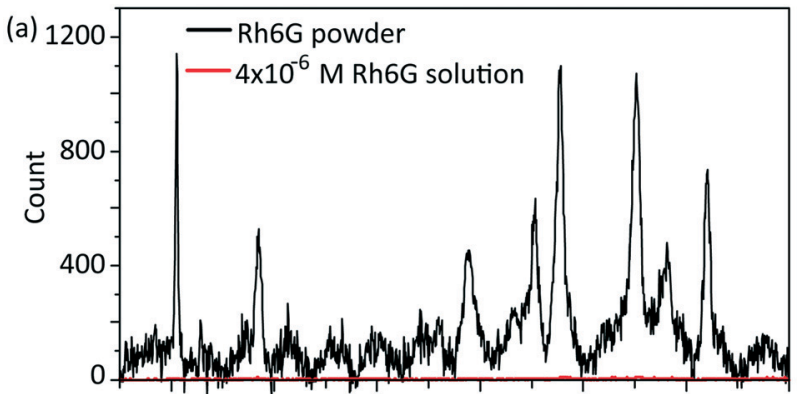

(b) $\left.\times 10^{4}\right]-26.6 \mathrm{~nm}$ CO-produced AuNPs

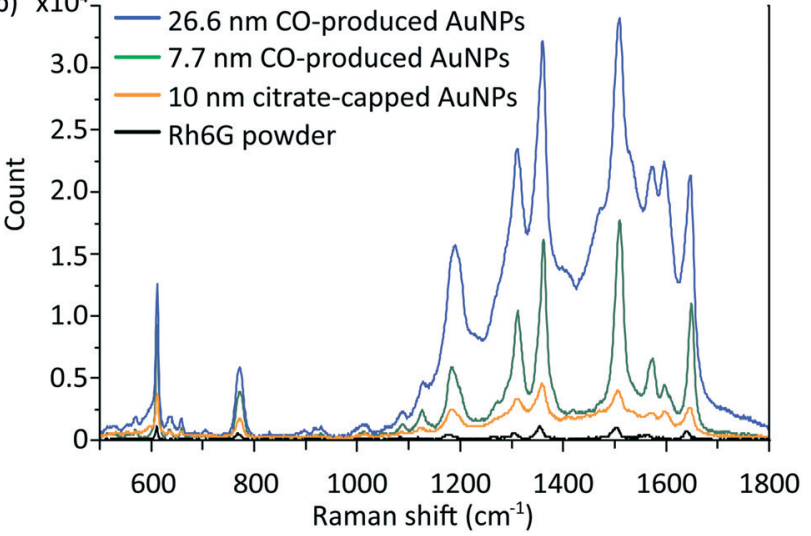

Fig. 4 (a) Typical Raman signal of Rh6G powder (in black) and $4 \times 10^{-6}$ $M$ Rh6G solution (in red, near background); (b) SERS spectra of $4 \times$ $10^{-6} \mathrm{M}$ Rh6G solution enhanced by $26.6 \mathrm{~nm}$ CO-produced gold nanoparticles (in blue), $7.7 \mathrm{~nm}$ CO-produced nanoparticles (in green) and 10 $\mathrm{nm}$ citrate-capped gold nanoparticles (in orange), compared to Rh6G powder (in black) without enhancement.

$\mathrm{nm}$ citrate-capped gold nanoparticles with AEF of $1.77 \times 10^{5}$, the enhancement of $26.6 \mathrm{~nm}$ CO-produced gold nanoparticles was similar (see Table S3†). However, considering the synthesis time of $30 \mathrm{~min}$ in a typical protocol of citrate-capped gold nanoparticles via the Turkevich method, ${ }^{5}$ the CO-produced gold nanoparticles are still attractive due to the shorter time ( $<4 \mathrm{~min})$ and room temperature synthesis. When the particle size was outside the optimal size range $(20-100 \mathrm{~nm})$, the COproduced gold nanoparticles showed better SERS performance than citrate-stabilised gold nanoparticles. Compared to $10 \mathrm{~nm}$ citrate-capped gold nanoparticles $(\mathrm{AEF}=2.99 \times$ $10^{4}$ ), the $7.7 \mathrm{~nm}$ CO-produced gold nanoparticles (obtained from $0.27 \mathrm{mM}$ initial concentration of gold precursor at $\mathrm{L} / \mathrm{G}=$ 10 in Fig. 2) gave nearly three times higher enhancement $\left(\mathrm{AEF}=1.06 \times 10^{5}\right)$, which is attributed to the narrower gap between particles and easier adsorption of analyte molecule onto the naked surface of gold nanoparticles.

\section{Synthesis of gold nanoparticles with various capping agents}

The synthesized gold nanoparticles without any capping agents (shown in Fig. 1c) were monitored by UV-Vis and proven to be stable for 1 week at room temperature and for at least one month when stored at $4{ }^{\circ} \mathrm{C}$. The reason for the stability of the uncapped nanoparticles is not clear. No CO was found on the surface of gold nanoparticles (as measured by IR spectroscopy, see Fig. S6†).

Longer shelf lives could be obtained by adding different capping agents, either before or immediately after the synthesis. Fig. 5 shows gold nanoparticles with different sizes obtained using different capping agents, namely trisodium citrate, polysorbate 80 (TWEEN 80), oleylamine and poly(ethyleneglycol) 2mercaptoethyl ether acetic acid (thiol-PEG-COOH). All experiments were performed at room temperature apart from the oleylamine-capped gold nanoparticles synthesis (for synthesis details see section 6 , ESI $\dagger$ ). The size of the citrate-capped gold nanoparticles $(11.6 \pm 1.6 \mathrm{~nm}, 14.0 \%)$ shown in Fig. 5a was higher compared to the no-capping-agent system $(7.7 \pm 0.3$ $\mathrm{nm}, 4.1 \%$ in Fig. $1 \mathrm{~b}$ ) for the same operation conditions. This is because adding the alkaline citrate increases the $\mathrm{pH}$ of the solution, which leads to a shift of equilibrium to the gold species with less reactivity ${ }^{8}$ and decrease of the nucleation rate. ${ }^{9}$ With fewer nuclei forming and higher amount of gold precursor available for growth, larger particle size was obtained. TWEEN 80 was used to change the surface tension of the solvent as a non-ionic surfactant, leading to smaller bubble size (insert in Fig. $5 \mathrm{~b}$ ) compared to that when no capping agents were used (Fig. S3 $\uparrow$ ). The enhanced mass transfer between gas and liquid due to the increased surface-tovolume ratio and the good protecting ability of TWEEN 80 produced gold seeds with size of $2.7 \pm 0.4 \mathrm{~nm}(14.6 \%)$ at residence time $4.2 \mathrm{~min}$ and TWEEN 80/gold precursor ratio of 0.5 (Fig. S7†). As TWEEN 80 has been shown to be a weaker reducing agent (reaction time of $6 \mathrm{~h}$ at room temperature)

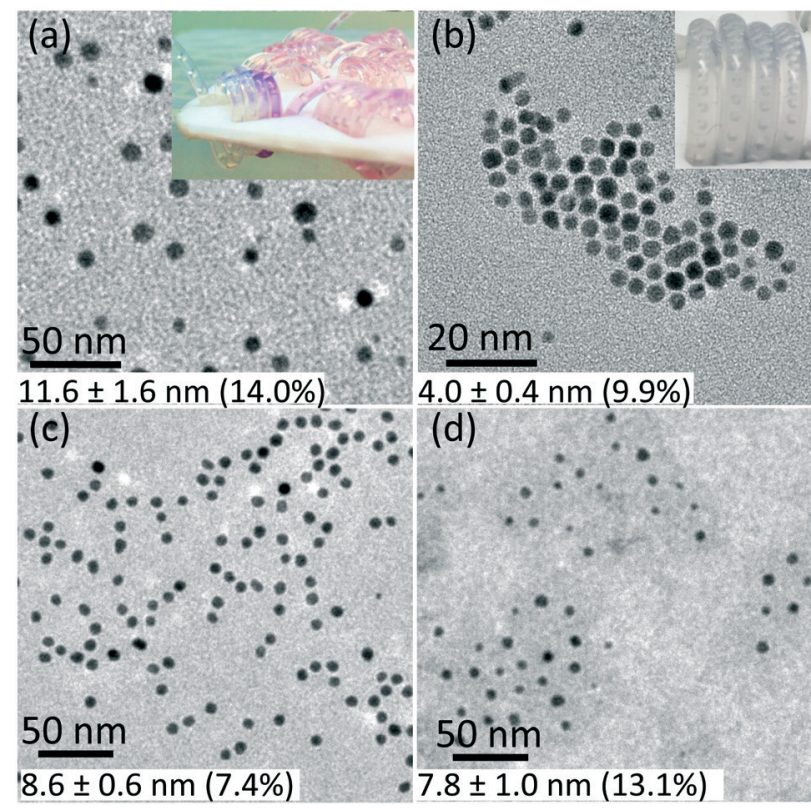

Fig. 5 TEM images of gold nanoparticles capped by a) trisodium citrate premixed with $\mathrm{HAuCl}_{4}$ (insert shows the flow pattern in the CFI), b) TWEEN 80 (insert shows the flow pattern in the $C F I), c$ ) oleylamine in octane and d) thiol-PEG-COOH. For experimental details see ESI. $\uparrow$ The values of average particle size and polydispersity were obtained by TEM. 
compared to CO for gold nanoparticles synthesis, ${ }^{23}$ seed particles subsequently grew to $4.0 \pm 0.4 \mathrm{~nm}(9.9 \%)$ inside the container reduced by excess TWEEN 80 within 8 days. Stability of the gold nanoparticles after growth $(4.0 \mathrm{~nm})$ was more than 1 month at room temperature.

Using the same set-up, hydrophobic gold nanoparticles could also be synthesized by using oleylamine as a capping agent at $100{ }^{\circ} \mathrm{C}$. The different synthesis procedure, including higher reaction temperature, led to spherical shape gold nanoparticles rather than gold nanowires formed via $\mathrm{CO}$ at $60{ }^{\circ} \mathrm{C}$ in previous batch synthesis. ${ }^{24}$ A TEM image of the synthesized gold nanoparticles with size of $8.6 \pm 0.6 \mathrm{~nm}(7.4 \%)$ is shown in Fig. 5c. A comparative experiment using $\mathrm{N}_{2}$ instead of CO was conducted under the same experimental conditions (Fig. S8, ESI $\dagger$ ). Nanowires formed without CO as observed for oleylamine reduction in previous literature. ${ }^{25}$ Thiol-PEG-COOH gold nanoparticles were also synthesized, because they are widely used in drug and gene delivery ${ }^{26,27}$ as relatively non-toxic carriers. They could be obtained with our system by post-synthetic modification methods. To synthesize PEG-capped gold nanoparticles, poly(sodium 4-styrenesulfonate) (PSS) was used during the CO reduction stage to stabilize the gold nanoparticles temporarily. Subsequently, thiol-PEG-COOH was added into the gold nanoparticle solution obtained and stirred overnight. Because of the stronger binding strength of thiols, the thiol-PEG-COOH was adsorbed onto the gold nanoparticles without size alteration (compared to PSS-capped gold nanoparticles with size of $7.8 \pm 1.2 \mathrm{~nm}$, $15.4 \%$ in Fig. S9b, ESI $\dagger$ ), and no further aggregation was observed (Fig. 5d).

\section{Conclusions}

We demonstrated a room temperature synthesis of gold nanoparticles with carbon monoxide in a microfluidic segmented flow system. The reducing strength of $\mathrm{CO}$ is between that of $\mathrm{NaBH}_{4}$ and citrate, which aids the rapid synthesis of sub-10 nm gold nanoparticles. The use of microfluidic segmented flow in a coiled flow inverter under optimised conditions can lead to monodisperse particles $(<5 \%)$. Our procedure can produce gold nanoparticles, whose size and hydrophilicity can be tuned by capping agents like citrate, TWEEN 80, oleylamine and thiol-PEG-COOH. Since this approach can produce highly controlled and impurity-free gold nanoparticles, it provides advantages for surface-enhanced Raman scattering and potentially many other applications.

\section{Conflicts of interest}

There are no conflicts of interest to declare.

\section{Acknowledgements}

The authors thank the EPSRC for financial support (EP/ M015157/1) through the Manufacturing Advanced Functional Materials (MAFuMa) scheme. $\mathrm{HH}$ acknowledges the financial support from UCL-CSC scholarship. We thank Dr. Tom Macdonald for his support with the IR measurement.

\section{References}

1 M.-C. Daniel and D. Astruc, Gold nanoparticles: assembly, supramolecular chemistry, quantum-size-related properties, and applications toward biology, catalysis, and nanotechnology, Chem. Rev., 2004, 104(1), 293-346.

2 N. T. K. Thanh and Z. Rosenzweig, Development of an aggregation-based immunoassay for anti-protein A using gold nanoparticles, Anal. Chem., 2002, 74(7), 1624-1628.

3 X. Huang, P. K. Jain, I. H. El-Sayed and M. A. El-Sayed, Gold nanoparticles: Interesting optical properties and recent applications in cancer diagnostics and therapy, Nanomedicine, 2007, 2(5), 681-693.

4 M. Brust, M. Walker, D. Bethell, D. J. Schiffrin and R. Whyman, Synthesis of thiol-derivatised gold nanoparticles in a two-phase liquid-liquid system, J. Chem. Soc., Chem. Commun., 1994, 0(7), 801-802.

5 J. Turkevich, P. C. Stevenson and J. Hillier, A study of the nucleation and growth processes in the synthesis of colloidal gold, Discuss. Faraday Soc., 1951, 11, 55-75.

6 A. Leifert, Y. Pan-Bartnek, U. Simon and W. Jahnen-Dechent, Molecularly stabilised ultrasmall gold nanoparticles: Synthesis, characterization and bioactivity, Nanoscale, 2013, 5(14), 6224-6242.

7 J. Wagner, T. R. Tshikhudo and J. M. Koehler, Microfluidic generation of metal nanoparticles by borohydride reduction, Chem. Eng. J., 2008, 135, S104-S109.

8 M. Wuithschick, A. Birnbaum, S. Witte, M. Sztucki, U. Vainio, N. Pinna, K. Rademann, F. Emmerling, R. Kraehnert and J. Polte, Turkevich in new robes: Key questions answered for the most common gold nanoparticle synthesis, ACS Nano, 2015, 9(7), 7052-7071.

9 J. K. Young, N. A. Lewinski, R. J. Langsner, L. C. Kennedy, A. Satyanarayan, V. Nammalvar, A. Y. Lin and R. A. Drezek, Size-controlled synthesis of monodispersed gold nanoparticles via carbon monoxide gas reduction, Nanoscale Res. Lett., 2011, 6(1), 428.

10 M. Taifur-Rahman, P. G. Krishnamurthy, P. Parthiban, A. Jain, C. P. Park, D.-P. Kim and S. A. Khan, Dynamically tunable nanoparticle engineering enabled by short contacttime microfluidic synthesis with a reactive gas, RSC Adv., 2013, 3(9), 2897-2900.

11 A. Günther, M. Jhunjhunwala, M. Thalmann, M. A. Schmidt and K. F. Jensen, Micromixing of miscible liquids in segmented gas-liquid flow, Langmuir, 2005, 21(4), 1547-1555.

12 M. Mridha and K. Nigam, Coiled flow inverter as an inline mixer, Chem. Eng. Sci., 2008, 63(6), 1724-1732.

13 S. K. Kurt, F. Warnebold, K. D. Nigam and N. Kockmann, Gas-liquid reaction and mass transfer in microstructured coiled flow inverter, Chem. Eng. Sci., 2017, 169, 164-178.

14 L. A. Pretzer, Q. X. Nguyen and M. S. Wong, Controlled growth of sub-10 nm gold nanoparticles using carbon 
monoxide reductant, J. Phys. Chem. C, 2010, 114(49), 21226-21233.

15 Y. Kang, X. Ye and C. B. Murray, Size- and shape-selective synthesis of metal nanocrystals and nanowires using $\mathrm{CO}$ as a reducing agent, Angew. Chem., Int. Ed., 2010, 49(35), 6156-6159.

16 H. du Toit, T. Macdonald, H. Huang, I. P. Parkin and A. Gavriilidis, Continuous flow synthesis of citrate capped gold nanoparticles using UV induced nucleation, RSC Adv., 2017, 7(16), 9632-9638.

17 F. Kettemann, A. Birnbaum, S. Witte, M. Wuithschick, N. Pinna, R. Kraehnert, K. Rademann and J. Polte, The missing piece of the mechanism of the Turkevich method: The critical role of citrate protonation, Chem. Mater., 2016, 28(11), 4072-4081.

18 X. Ji, X. Song, J. Li, Y. Bai, W. Yang and X. Peng, Size control of gold nanocrystals in citrate reduction: The third role of citrate, J. Am. Chem. Soc., 2007, 129(45), 13939-13948.

19 A. Campion and P. Kambhampati, Surface-enhanced Raman scattering, Chem. Soc. Rev., 1998, 27(4), 241-250.

20 X.-Y. Zhang, A. Hu, T. Zhang, W. Lei, X.-J. Xue, Y. Zhou and W. W. Duley, Self-assembly of large-scale and ultrathin silver nanoplate films with tunable plasmon resonance properties, ACS Nano, 2011, 5(11), 9082-9092.
21 E. Le Ru and P. Etchegoin, Principles of Surface-Enhanced Raman Spectroscopy: and related plasmonic effects, Elsevier, Oxford, 2008.

22 N. R. Jana and T. Pal, Anisotropic metal nanoparticles for use as surface-enhanced Raman substrates, Adv. Mater., 2007, 19(13), 1761-1765.

23 T. Premkumar, D. Kim, K. Lee and K. E. Geckeler, Polysorbate 80 as a tool: Synthesis of gold nanoparticles, Macromol. Rapid Commun., 2007, 28(7), 888-893.

24 Y. Kang, X. Ye and C. B. Murray, Size-and shape-selective synthesis of metal nanocrystals and nanowires using $\mathrm{CO}$ as a reducing agent, Angew. Chem., 2010, 122(35), 6292-6295.

25 H. Feng, Y. Yang, Y. You, G. Li, J. Guo, T. Yu, Z. Shen, T. Wu and B. Xing, Simple and rapid synthesis of ultrathin gold nanowires, their self-assembly and application in surfaceenhanced Raman scattering, Chem. Commun., 2009(15), 1984-1986.

26 J. M. Bergen, H. A. Von Recum, T. T. Goodman, A. P. Massey and S. H. Pun, Gold nanoparticles as a versatile platform for optimizing physicochemical parameters for targeted drug delivery, Macromol. Biosci., 2006, 6(7), 506-516.

27 V. Dixit, J. Van den Bossche, D. M. Sherman, D. H. Thompson and R. P. Andres, Synthesis and grafting of thioctic acid- PEG- folate conjugates onto Au nanoparticles for selective targeting of folate receptor-positive tumor cells, Bioconjugate Chem., 2006, 17(3), 603-609. 